\title{
Evaluation of Health Level of Land-use Ecosystem Based on GIS Grid Model
}

\author{
Wei $\mathrm{He}^{*}(* *) \dagger$, Zheng $\mathrm{Li}^{*}(* *)$ and Dingqian Jing*(**) \\ *College of Geography and Resources Science, Sichuan Normal University, Chengdu 610101, People's Republic \\ of China \\ **Key Lab of Land Resources Evaluation and Monitoring in Southwest, Ministry of Education, Sichuan Normal \\ University, Chengdu 610101, People's Republic of China \\ $\dagger$ Corresponding author: Wei He; scdlwhe@ sicnu.edu.cn
}
Nat. Env. \& Poll. Tech. Website: www.neptjournal.com
Received: 18-03-2020
Revised: 17-4-2020
Accepted: 15-06-2020

\section{Key Words:}
Land-use
GIS grid model
Spatial exploratory analysis Geographic detector

\begin{abstract}
The evaluation of health level of land-use ecosystem provides important support for the regional health and social-economic sustainable development. To measure and study the granularity characteristics and spatial differentiation law of ecological health level of land-use in Yibin City, based on PSR model, taking kilometre grid as an evaluation unit, spatial exploration method was used to reveal its spatial differentiation law, and the decisive force of each factor was visualized through the factor detector. The results show that: (1) The health level of the land-use ecosystem in Yibin City is generally good, and the regional development is relatively balanced, but there are significant differences between the municipal districts and suburban counties. The average index of comprehensive health level of landuse ecosystem fluctuates around 0.60 , the land for health level accounts for $46.07 \%$ of the total area, the land for sub-health level accounts for $29.78 \%$, the land for unhealthy level accounts for $24.15 \%$. (2) The health level of land-use ecosystem had a strong spatial correlation, which was mainly positive, and there was a significant spatial agglomeration pattern, dominated by HH type or LL type clusters. (3) The difference of human activities was the main factor that affects the spatial differentiation of ecological health level of land-use in the whole city, followed by the difference of natural system resilience, and the other factors were soil properties, landform and policy regulation. Finally, it was concluded that tightening the upper limit of capacity, holding the ecological bottom line, insisting on the intensive utilization of land, optimizing the spatial layout of "production, life and ecology", adjusting the industrial structure, and developing ecotourism will become the necessary measures for Yibin city to improve the ecological health level of land-use and build a famous ecological city of landscape culture.
\end{abstract}

\section{INTRODUCTION}

The health level of land-use ecosystem refers to a state in which the land under the jurisdiction can maintain the normal operation of self-structure and functions when used by people. So that the symbiosis process among land, human, biology and external environment can be continuously developed (Zhang et al. 2011). In recent years, with prominent problems such as resource depletion and environmental pollution, the ecological health of land-use, as a new goal of land ecological environment protection and sustainable development, has attracted much attention. Therefore, it is an urgent task for regional health and sustainable development of the social economy to evaluate the ecological health of land-use and formulate reasonable control measures.

Since the end of the 20th century, there are few studies on the evaluation of health level of land-use ecosystem at home and abroad, mainly focusing on the connotation, mechanism, level and regulation of ecological health of land-use (Gao et al. 2017, Zhang \& Shi 2010), based on single land ecosystem and basic administrative areas such as city, county (district), township (town, sub-district) (Wei 2017), involving cities (Ma et al. 2014), wetlands (Zhu et al. 2012) grasslands (Zhao et al. 2017) and rivers (Hao et al. 2014), using building an index evaluation system of land-use ecological health based on vitality-organization-resilience (VOR) theory from the aspects of vitality, organization, resilience and function (Liu et al. 2017).

Yibin City, a hilly area in the upper reaches of the Yangtze River, was taken as the research object. Based on the PSR model of "human-land interaction" considering the interaction between land ecosystem and human activities, the grid model was used to transform the remote sensing data, landuse data and panel data in a unified way to expand the single ecosystem to a composite ecosystem while realizing the compatibility of multiple data and the refinement of spatial accuracy of evaluation, to establish an appropriate ecological health evaluation system for land-use. The ecological health level of land-use in each grid was measured taking kilometre grid as the basic measure unit; ESDA space exploration 
technology was used to reveal the spatial differentiation law of land-use ecological health level in grid scale, and factor detector was used to show the decisive power of each factor directly. The purpose of this paper is to enrich the research content of land-use ecological health evaluation and to provide targeted countermeasures for improving the ecological health level of regional land-use.

\section{RESEARCH AREA, DATA SOURCES AND PREPROCESSING}

\section{Overview of Research Area}

Yibin City, located in the southeast of Sichuan Province, between $103^{\circ} 36^{\prime} \mathrm{E}$ and $105^{\circ} 20^{\prime} \mathrm{E}, 27^{\circ} 50^{\prime} \mathrm{N}$ and $29^{\circ} 16^{\prime} \mathrm{N}$, has two districts and eight counties, with a total area of $13,000 \mathrm{~km}^{2}$ (Fig. 1). It is the transition from Sichuan basin to Yunnan-Guizhou Plateau, with the terrain dominated by middle and low mountains and hills, alternated valleys and flatlands, and the landscape distribution pattern, which is high in the southwest and low in the northeast (Liu et al. 2017, Zhao et al. 2015). In 2018, Yibin city's population totalled 5.5429 million, with a GDP of 152.594 billion yuan, the urbanization rate has reached $48.5 \%$. With the development of social economy, also increases the pressure of regional resources and environment, and brings new challenges to the sustainable development of regional land ecology. Therefore, under the background of the planning strategy of regional land ecological development, it is of practical significance to carry out the research on the evaluation of health level of the land-use ecosystem in the city for the restoration and protection of the land ecological environment and the establishment of ecological protective screens.

\section{Data Source and Pre-processing}

Social and economic statistics in this study are mainly from the information published in Yibin Statistical Yearbook. The data of land-use status were interpreted by Landsat ETM + and OLI images downloaded from the data centre for resources and environmental sciences of Chinese Academy of Sciences (http://www.resdc.cn), with a spatial resolution of $30 \mathrm{~m} \times 30 \mathrm{~m}$. Considering the needs of research, the land-use types were determined as cultivated land, forest land, grassland, urban construction land, rural residential land, water area, independent industrial and mining district and land for transportation. DEM data came from ASTER-GDEMV2 digital elevation data with a resolution of $30 \mathrm{~m}$ provided by NASA (search.earthdata.nasa.gov). The tool of creating fishnet in ArcGIS 10.2 was used to generate the grid of $1 \mathrm{~km}$ $\times 1 \mathrm{~km}$, and there were a total of 13,307 grids generated in Yibin City.

\section{MATERIALS AND METHODS}

\section{Construction of PSR Evaluation Index System}

The internal health of the land ecosystem is related to people's survival and sustainable development of society.

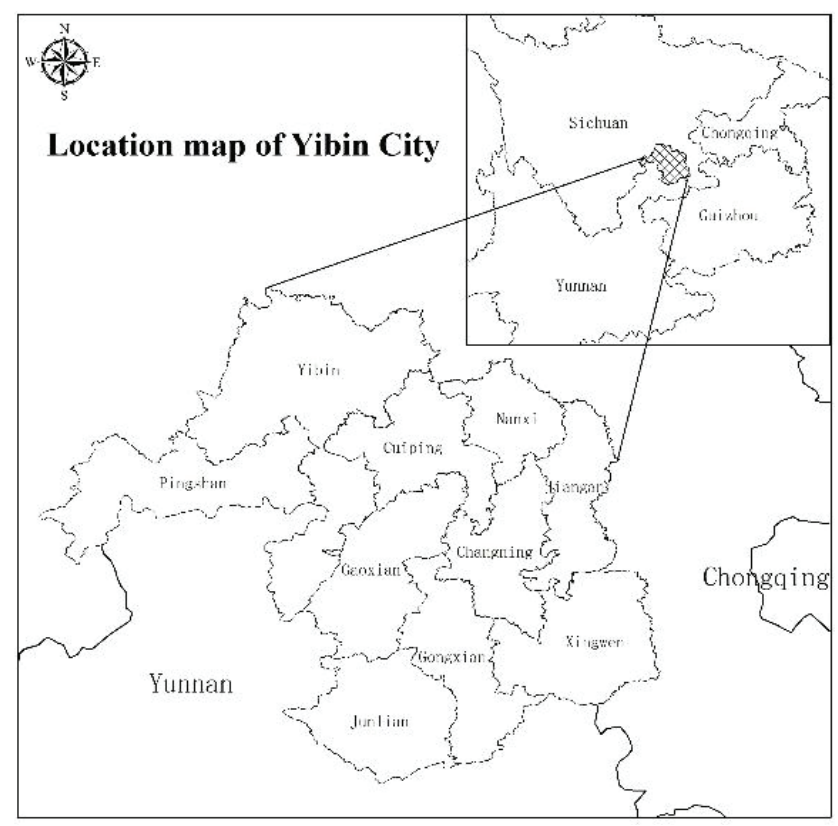

Fig. 1: Geographical location of the study area 
The interaction between land ecosystem and human activities must be considered comprehensively when establishing the indicator system. Based on the PSR model (Zhao et al. 2015, Xu et al. 2010), build the evaluation index system for the health level of the land-use ecosystem in Yibin City.

"Pressure" refers to the defect of land and resources and the impact of human activities on land and surrounding environment, which is measured by terrain fragmentation, soil erosion, population density and stress index of human activities (He et al. 2015). "State" refers to the energy and activity of land ecosystem (Jiang et al. 2009), which is measured by Landscape diversity index (Chen 2007), ecological resilience (Pan et al. 2004), ecosystem service values (Xie et al. 2008). "Response" refers to the policy measures taken by human beings for land ecological restoration, mainly including the amount of environmental protection investment and the proportion of the tertiary industry in GDP. Details are provided in Tables 1 and 2 .

\section{Spatial Exploratory Analysis}

Spatial exploratory analysis is a kind of data spatial descrip-

Table 1: Ecosystem health evaluation index system.

\begin{tabular}{|c|c|c|c|c|c|c|c|}
\hline Target layer & $\begin{array}{l}\text { Criterion } \\
\text { layer }\end{array}$ & & & Index layer & Formulas & Safety trend & Weight \\
\hline \multirow{10}{*}{$\begin{array}{l}\text { Land ecosys- } \\
\text { tem healthw }\end{array}$} & \multirow{4}{*}{\multicolumn{2}{|c|}{ Pressure }} & P1 & Soil erosion & - & Negative & 0.089 \\
\hline & & & P2 & Terrain fragmentation & $\mathrm{P} 2=1 / \cos \alpha$ & Negative & 0.177 \\
\hline & & & P3 & Population density (person/km²) & $\mathrm{P} 3=\mathrm{r}_{i} / m_{i}$ & Negative & 0.102 \\
\hline & & & P4 & Stress index of human activities & $\mathrm{P} 4=\sum_{i=1}^{\mathrm{n}} t_{i} * q_{i} / A$ & Negative & 0.081 \\
\hline & \multirow[t]{4}{*}{ State } & Vitality & S1 & $\begin{array}{l}\text { Normalized differential vegetation } \\
\text { index }\end{array}$ & $\mathrm{S} 1=\frac{N I R-R}{N I R+R}$ & Positive & 0.090 \\
\hline & & Organization & $\mathrm{S} 2$ & Landscape diversity index & $S 2=-\sum_{i=1}^{\mathrm{n}} \frac{t_{i}}{A} \ln \left(\frac{t_{i}}{A}\right)$ & Positive & 0.089 \\
\hline & & Resilience & S3 & Ecological resilience & $S 3=S * \sum_{i=1}^{n} \frac{\mathrm{t}_{i} * p_{i}}{A}$ & Positive & 0.087 \\
\hline & & Function & S4 & Ecosystem service values & $S 4=\sum_{i=1}^{\mathrm{n}} t_{i}^{*} v_{i}$ & Negative & 0.087 \\
\hline & \multirow[t]{2}{*}{ Response } & & R1 & $\begin{array}{l}\text { Investment in environmental pro- } \\
\text { tection ( } 104 \text { yuan) }\end{array}$ & - & Positive & 0.097 \\
\hline & & & R2 & $\begin{array}{l}\text { Proportion of tertiary industry in } \\
\text { GDP }(\%)\end{array}$ & $\mathrm{R} 2=S / G D P$ & Positive & 0.101 \\
\hline
\end{tabular}

Note: $n=$ Number of land-use types; a =Average slope of cell grid; $r_{i}=$ Population of each district and county; $m_{i}=$ Area of the administrative region; $t_{i}=$ Area of the $\mathrm{i}^{\text {th }}$ type of land-use; $q_{i}=$ Stress intensity parameters of human activities of the $\mathrm{i}^{\text {th }}$ type of land-use; $\mathrm{R}=$ Reflection value of red band; NIR= Reflection value of infrared band; $V_{i}=$ Ecosystem service value of the unit area of the $\mathrm{i}^{\text {th }}$ type of land-use; $p_{i}=$ Resilience score of the $\mathrm{i}^{\text {th }}$ type of land-use; $A=$ Total area of evaluation unit; $S=$ Output value of the tertiary industry.

Table 2: Comparison of relevant parameters of land-use type.

\begin{tabular}{|llllllll}
\hline \multicolumn{1}{c}{$\begin{array}{c}\text { Types of } \\
\text { land-use }\end{array}$} & $\begin{array}{l}\text { Cultivated } \\
\text { land }\end{array}$ & $\begin{array}{l}\text { Forest } \\
\text { land }\end{array}$ & $\begin{array}{l}\text { Grass- } \\
\text { land } \\
\text { Relevant index } \\
\text { parameters }\end{array}$ & $\begin{array}{l}\text { Urban } \\
\text { construction } \\
\text { land }\end{array}$ & $\begin{array}{l}\text { Rural } \\
\text { residential area }\end{array}$ & $\begin{array}{l}\text { Water } \\
\text { area }\end{array}$ & $\begin{array}{l}\text { Independent industrial and } \\
\text { mining district and land for } \\
\text { transportation }\end{array}$ \\
\hline $\begin{array}{l}\text { Stress intensity of human } \\
\text { activities }\end{array}$ & 0.55 & 0.10 & 0.23 & 0.95 & 0.68 & 0.12 & 0.68 \\
$\begin{array}{l}\text { Parameters of ecological } \\
\text { resilience }\end{array}$ & 0.50 & 0.90 & 0.60 & 0.40 & 0.40 & 0.80 & 0.40 \\
$\begin{array}{l}\text { Ecosystem service value } \\
\left(10^{4} \text { yuan } / \mathrm{km}^{2}\right)\end{array}$ & 7.93 & 173.00 & 20.00 & 0.00 & 0.00 & 732.00 & 0.00 \\
\hline
\end{tabular}


tion and visual analysis method which emphasizes the spatial correlation measure as the core and aims at revealing the spatial interaction mechanism of research objects, divided into global autocorrelation and local autocorrelation. Global spatial autocorrelation is mainly used to explore the distribution characteristics of attribute data values in the whole regional space. The global Moran's I index is a desirable measure of response distribution, which is between -1 and 1. If it is greater than 0 , it means positive correlation; if it is less than 0 , it means a negative correlation. Local spatial autocorrelation is mainly used to analyze the distribution pattern of attribute values of each unit in the heterogeneous space, and measure the degree of local spatial correlation between each region and its surrounding regions. The larger local Moran's I statistic represents the spatial agglomeration of regional units with similar observations, while smaller values represent spatial agglomeration of regional units with different values (Liu et al. 2018).

The calculation formula of global Moran's I index is as follows:

$$
I=n \sum_{i=1}^{n} \sum_{j=1}^{n} w_{i j}\left(x_{i}-\bar{x}\right)\left(x_{j}-\bar{x}\right) / \sum_{i=1}^{n} \sum_{j=1}^{n} w_{i j} \sum_{j=1}^{n}\left(x_{i}-\bar{x}\right)^{2}
$$

The calculation formula of local Moran's I index is as follows:

$$
I_{i}=\left(x_{i}-\bar{x}\right) \sum_{j=1}^{n} w_{i j}\left(x_{j}-\bar{x}\right) / \frac{1}{n} \sum_{i}\left(x_{i}-\bar{x}\right)^{2}
$$

Where, $w_{i j}$ is the weight matrix based on the spatial adjacency principle; $x_{i}$ and $x_{i}$ are evaluation values of the $i^{\text {th }}$ and $j^{\text {th }}$ unit; $\bar{x}$ is the mean of the $n^{\text {th }}$ evaluation value.

\section{Geographical Detector Analysis}

The geographical detector is a kind of econometric statistical analysis method proposed by Wang et al. (2002) of Chinese Academy of Sciences to check the spatial differentiation of single-variable and to detect the causal relationship between two variables by checking the consistency of spatial distribution of two variables, mainly including factor detector, risk detector, ecological detector and interaction detector. The factor detector was used to detect and identify the driving force of the spatial differentiation law of the comprehensive evaluation index of land ecosystem health in Yibin City, which was, in essence, comparing the total variance of the factor index in different categories and regions with the total variance in the whole region. The calculation formula is as follows:

$$
P_{D, F}=1-\frac{1}{n * \sigma_{F}^{2}} \sum_{i=1}^{m} n_{D, i} * \sigma_{F_{D, i}}^{2}
$$

Where, $P_{D, F}=$ Detection index of influence factor $D$ on the spatial differentiation law of comprehensive health level of the land ecosystem in Yibin City.

$n_{D, i}=$ Number of samples in the secondary area

$n=$ Number samples in the whole region;

$\mathrm{s}_{\mathrm{F}}^{2}=$ Variance of spatial differentiation rule of comprehensive evaluation index of land ecosystem health;

$M=$ Number of samples in the secondary region;

$\sigma_{F_{D, i}}^{2}=$ Variance in the secondary region;

$P_{D, F}$ is between 0 and 1 , the larger the value is, the greater the influence of the index on the spatial differentiation of land-use ecological health level.

\section{RESULTS AND ANALYSIS}

\section{Analysis of Health Level of Land-use Ecosystem}

To reflect the health level of the land-use ecosystem of each district and county in Yibin City, the health indexes of the land-use ecosystem within the grid were put on the ArcGIS

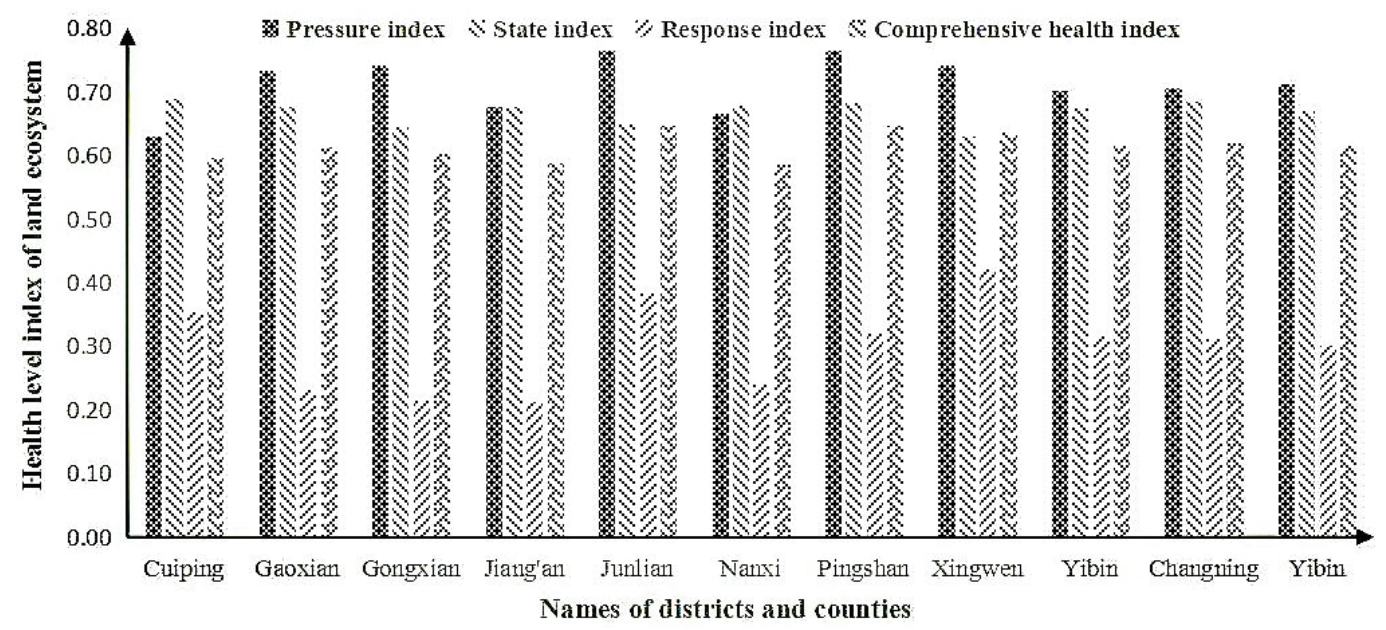

Fig. 2: Health level index of land-use ecosystem in each district and county of Yibin. 
Table 3: Classification of the health status of land-use ecosystem.

\begin{tabular}{|c|c|c|c|c|}
\hline $\begin{array}{l}\text { Health } \\
\text { status }\end{array}$ & $\begin{array}{l}\text { Classification } \\
\text { standard }\end{array}$ & Area $\mathrm{km}^{2}$ & $\begin{array}{l}\text { Area } \\
\text { percentage (\%) }\end{array}$ & Regional characteristics \\
\hline Healthy & {$[0.63,0.73]$} & 6131 & 46.07 & $\begin{array}{l}\text { Reasonable ecological structure, strong system vitality, small external pres- } \\
\text { sure, no ecological abnormality, perfect ecosystem function, stable system and } \\
\text { sustainable state }\end{array}$ \\
\hline $\begin{array}{l}\text { Sub- } \\
\text { healthy }\end{array}$ & {$[0.59,0.63)$} & 3962 & 29.78 & $\begin{array}{l}\text { Relatively reasonable ecological structure, stable system, large external } \\
\text { pressure, more ecologically sensitive areas, a small number of ecological } \\
\text { abnormalities, basic ecological functions, and sustainable state }\end{array}$ \\
\hline Unhealthy & {$[0.38,0.59)$} & 3214 & 24.15 & $\begin{array}{l}\text { Defects in the ecological structure, low system vitality, high external pressure, } \\
\text { many ecological abnormalities, weak ecological function to meet the needs of } \\
\text { maintaining the ecosystem, and degradation of the ecosystem }\end{array}$ \\
\hline
\end{tabular}

platform, and the average index of the health level of each district and county was obtained by using the summary statistical data tool (Fig. 2). Fig. 2 shows the comprehensive health status, as well as pressure, state and response subsystems of the land ecosystem of each district and county in Yibin City. In 2018, the average index of comprehensive health level of the land-use ecosystem in Yibin City fluctuated around 0.60. Junlian County, Pingshan County and Xingwen County exceeded the city's average, with the highest value of 0.65 (Pingshan County and Xingwen County); other districts and counties were slightly lower than the average level, with the lowest of 0.59 (Nanxi District).

It is necessary to deal with the differences in ecological health degree of land-use in the study area at different levels to clarify them. Natural breaks (Jenks) method in ArcGIS was used to divide the values of ecosystem health level into different discrete classes by comparing and analysing the GVF (the Goodness of Variance Fit) value. The comprehensive index of land-use ecosystem health level in Yibin City was divided into three levels, which respectively represent different health conditions, in order of healthy, sub-healthy and unhealthy. The regional characteristics of each level refer to the definitions of areas with different health level of the land ecosystem (Xu et al. 2010) (Table 3).

According to the classification standard, the health level of the land-use ecosystem of Yibin City was classified and evaluated.

It is observed from Fig. 4 that the areas with unhealthy land ecosystem were $6,131 \mathrm{~km}^{2}$, accounting for $24.15 \%$ of the total. These are mainly concentrated in the transition area between the plain and hilly area in the northeast of Yibin City and the plateau and basin in the south. Where there were unreasonable ecological structure and low vitality, large areas of abnormal ecological environment, and damaged ecosystem to some extent.

The area of regions in sub-healthy level was larger than that in unhealthy level, accounting for $29.78 \%$ of the total area, which was mainly distributed in Cuiping District, Nanxi district and Jiang' an County, indicating that although there were many sensitive areas in the land ecosystem of the city, they had normal ecological functions and sustainable ecological economy.

The area of regions in healthy level was $6,131 \mathrm{~km}^{2}$, accounting for $46.07 \%$ of the total area, which was mainly distributed in the middle and west of Pingshan County, the middle and south of Junlian county and Xingwen County. The main work in these places is to maintain and prevent.

\section{Spatial Exploratory Analysis on Health Level of Land- use Ecosystem}

Moran's I was selected as the evaluation standard of the spatial difference law for the health level of the land-use ecosystem by using the spatial exploratory analysis method, revealing the characteristics of the spatial agglomeration pattern. The LISA cluster map was drawn at the significance level of 5\% (Fig. 4B) according to Moran's I index of health level of the land-use ecosystem. The ecosystem by using the spatial exploratory analysis method revealed the characteristics of the spatial agglomeration pattern. The LISA cluster map was drawn at the significance level of 5\% (Fig. 4B) according to Moran's I index of health level of the land-use ecosystem.

Fig. 4 A shows that Moran's I value of health level of the land-use ecosystem in Yibin City was 0.447179 in 2015. According to the distribution of Moran scattered points, the relationship between each region and a geographical phenomenon or attribute value in the surrounding region can be qualitatively determined. Points with strong spatial positive correlation will fall into the HH ("high-high") and LL ("lowlow") quadrants, i.e., the health level of the areas around those with high health level will be high, the same to areas with low level, which are homogeneous; points with strong spatial negative correlation will fall into the LH ("low- high") and HL ("high-low") quadrants, that is, the health level of the region is opposite to that of the surrounding areas, which are heterogeneous. According to the distribution of attribute values, the health level of the land-use ecosystem in Yibin City has a strong spatial correlation. 


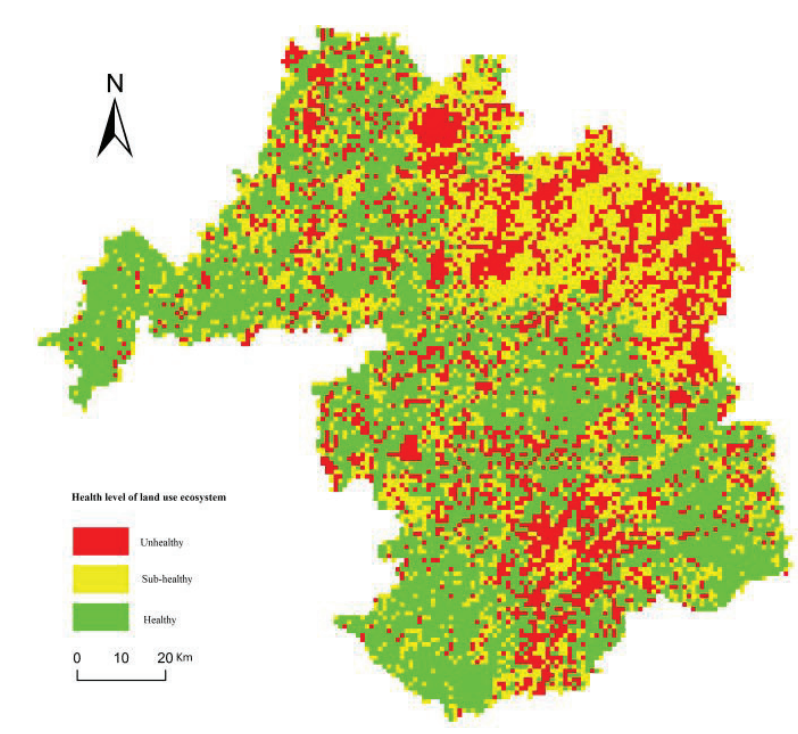

Fig. 3: Ecological health of the land-use in Yibin City.
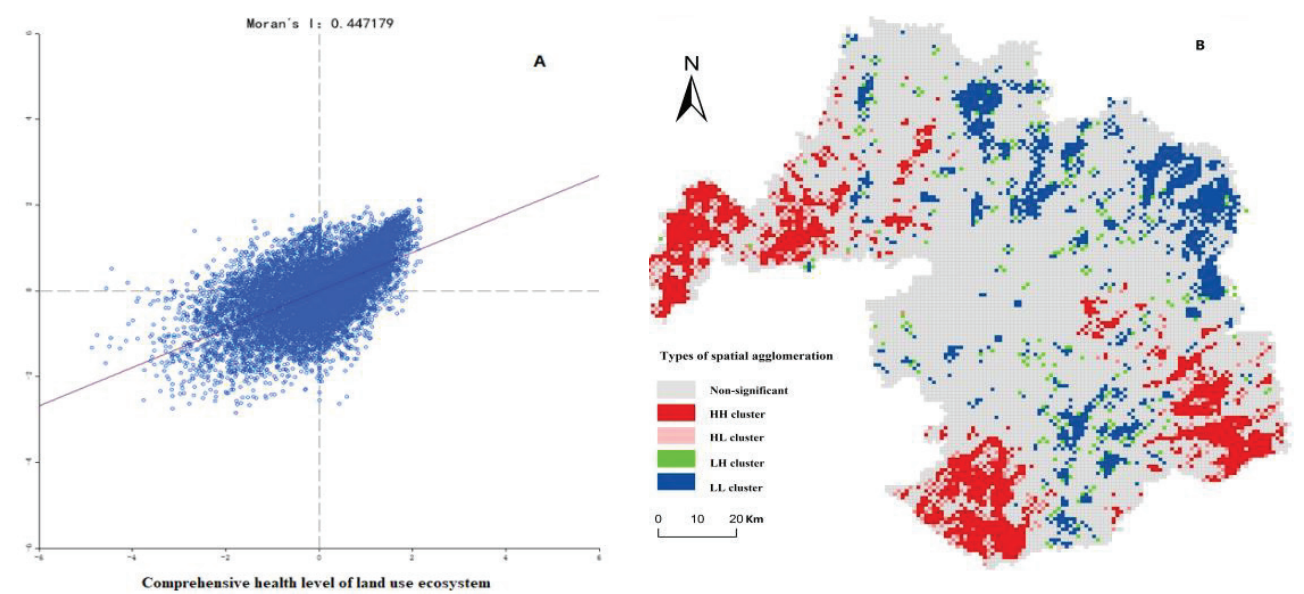

Fig. 4: Moran scatter diagram A and LISA cluster Diagram B of ecological health level of land-use in Yibin City.

It is observed from Fig. 4B that the health level of the land-use ecosystem in Yibin City was mostly non-significant in space, and those with spatial correlation were mainly positive, mainly high-value or low-value clusters. HH (high-high cluster) is distributed in the east and west of Pingshan County, the middle and south of Xingwen County, and the middle and west of Junlian County. In the future development, the ecological protection project should be put in the first place, to ensure the ecological non-degradation of the whole county.

LL (low-low cluster) is scattered in the northeast and south of Yibin City, mainly including Cuiping District, Nanxi District, Jiangan County, Yibin County and Gongxian County. The LL type area should develop new leading industries according to local conditions based on ecological economy and optimization of the land-use structure.

\section{Analysis of the Influencing Factors of Spatial Differentiation of Health Level of Land-use Ecosystem}

The ecological health level of land-use is the result of the combined action of regional natural factors and human factors. Resilience and function" index system was selected as the geographic exploration variables of the spatial differentiation of the ecological health level of land-use, calculated the decisive power values of each influencing factor on the spatial differentiation of health level of land-use ecosystem respectively.

It is observed from Table 4 that value of the geographic detector of stress from human activities is 0.350 , which is far greater than other factors, indicating that the difference of human activities is the main reason for the spatial dif- 
Table 4: Geographical exploration results of spatial differentiation determination of health level of land-use ecosystem by various influencing factors.

\begin{tabular}{|c|c|c|c|c|c|}
\hline & \multirow[t]{2}{*}{ Index level } & \multicolumn{3}{|c|}{ Threshold values } & \multirow[t]{2}{*}{$\mathrm{P}$ value } \\
\hline & & Level I areas & Level II areas & Level III areas & \\
\hline $\mathrm{P} 1$ & Soil erosion & {$[0,0.330)$} & {$[0.330,0.667)$} & {$[0.667,1]$} & 0.208 \\
\hline $\mathrm{P} 2$ & Terrain fragmentation & {$[0,0.842)$} & {$[0.842,0.931)$} & {$[0.931,1]$} & 0.064 \\
\hline P3 & Population density (person $/ \mathrm{km}^{2}$ ) & {$[0,0.561)$} & {$[0.561,0.769)$} & {$[0.769,1]$} & 0.184 \\
\hline P4 & Stress index of human activities & {$[0,0.085)$} & {$[0.085,0.500)$} & {$[0.500,1]$} & 0.350 \\
\hline $\mathrm{S} 1$ & Normalized differential vegetation index & {$[0,0.675)$} & {$[0.675,0.916)$} & {$[0.916,1]$} & 0.032 \\
\hline S2 & Landscape diversity index & {$[0,0.210)$} & {$[0.210,0.730)$} & {$[0.730,1]$} & 0.296 \\
\hline S3 & Ecological resilience & {$[0,0.0017)$} & {$[0.0017,0.110)$} & {$[0.110,1]$} & 0.318 \\
\hline S4 & Ecosystem service value & {$[0,0.028)$} & {$[0.028,0.237)$} & {$[0.237,1]$} & 0.315 \\
\hline $\mathrm{R} 1$ & Investment in environmental protection (104 yuan) & {$[0,0.225)$} & {$[0.225,0.553)$} & {$[0.553,1]$} & 0.054 \\
\hline $\mathrm{R} 2$ & Proportion of tertiary industry in GDP $(\%)$ & {$[0,0.364)$} & {$[0.364,0.633)$} & {$[0.633,1]$} & 0.005 \\
\hline
\end{tabular}

ferentiation of ecosystem health level. By the end of 2018, the area of cultivated land and construction land in Yibin City had reached $36.69 \%$ and $7.02 \%$ respectively, but there were significant differences among districts and counties. The different pressure of human activities on land leads to the destruction of regional ecological environment and the imbalance of the ecological system. Therefore, it is urgent to control the population, reduce the direct destruction of land by human activities.

The difference in resilience of the natural system is the secondary reason that affects the spatial differentiation of ecosystem health level. The values of ecological resilience, ecosystem service value and landscape diversity index were $0.318,0.315$ and 0.296 , respectively, indicating that the ecological health status was affected by the resilience of the system itself. Although Yibin has a large proportion of arable land and construction land, there are various types of land. In particular, the area of grassland and forest land accounts for $41.74 \%$ of the total area of the region, which strong self-regulation and self-restoration capacity of the ecosystem. In the process of future development, should adjust the structure of land-use, optimize the spatial layout of "production, life and ecology", activate the stock, strictly observe the "red line" of cultivated land, increase the ecological land, adhere to the road of sustainable development, and promote the internal resilience of the ecosystem.

Soil properties, terrain factors and policy regulation are the other reasons for the spatial differentiation of ecosystem health level. The hilly landform brings about different regional natural geographical characteristics, and different types of soil erosion and terrain fragmentation, as a consequence, the above factors lead to obvious differences in the feedback of land ecosystem. Therefore, the city must implement a strict ecological environment protection system, severely crack down on the destruction of the ecological environment, vigorously develop science and technology, actively adjust the industrial structure, increase the proportion of the tertiary industry, reduce the pollution and damage of the primary and secondary industries to the soil, to build the ecological protection barrier of the upper reaches of the Yangtze River.

\section{DISCUSSION AND CONCLUSIONS}

Evaluating the health level of the land-use ecosystem is the premise and foundation of planning for land space renovation. For spatial exploratory analysis, geographical detector model was used to explore the spatial distribution characteristics of the ecosystem health status of land-use in Yibin City, and its spatial differentiation law was explained by combining quantitative and qualitative methods. Based on the existing research results, firstly, the PSR model and the theory of vitality, organization, resilience and function were organically combined and improved to establish a comprehensive health assessment index system of land ecological security in line with the actual situation of Yibin. Then, the health indexes were calculated by $1 \mathrm{~km} \times 1 \mathrm{~km}$ grid, and the spatial differentiation law was revealed by ESDA method. Finally, the decisive power of each factor was displayed by factor detector. All the above is the inheritance and development of previous research results. From the comparison of the results of this study, the temporal and spatial evolution law of health level of the land-use ecosystem is more in line with the regional reality (Huang et al. 2019), which also confirms that human activities are the important factors affecting land ecological security (Wei et al. 2020).

However, there are still many shortcomings: First, the evaluation index system is not perfect. The ecosystem is complex but was measured only by 10 indicators, neglecting NPP, soil pollution and other factors reflecting its attributes. At the same time, due to the availability of data, the response indexes were less, which needs to be further improved. 
Second, the stress intensity of human activities, ecological resilience and ecosystem service value were the factors determined by reference to the existing research results. If the reference standards are different, the calculated values will be different. Therefore, it needs to be corrected according to the actual situation of Yibin City. Third, to facilitate the transformation and compatibility of multiple data, enrich the attribute dimensions of evaluation units, and refine the spatial accuracy of evaluation area, the grid of $1 \mathrm{~km} \times 1 \mathrm{~km}$ was used as the basic evaluation unit, but the influence of administrative boundaries, data accuracy, and data processing convenience on the grid size was not considered. Fourth, adding the content of time series analysis may reveal the temporal and spatial evolution of health assessment of land-use ecosystem.

Following conclusions can be drawn from the study.

1. The health level of the land-use ecosystem in Yibin City is generally good, and the regional development is relatively balanced, but there are significant differences between the municipal districts and suburban counties. The average index of comprehensive health level of the land-use ecosystem in Yibin City fluctuates around 0.60 , and the land for health level accounts for $46.07 \%$ of the total area, the land for sub-health level accounts for $29.78 \%$ of the total area, the land for unhealthy level accounts for $24.15 \%$ of the total area. The main reason is that the land-use structure of the central city and suburban counties is different, and the impact of human activities on the land ecosystem is also different. The large area of urban construction land and the small amount of ecological land lead to the poor ability of self-regulation and self-recovery in the ecosystem.

2. The health level of the land-use ecosystem in Yibin City was mostly non-significant in space, and those with spatial correlation were mainly positive, mainly high-value or low-value clusters. HH type was distributed in the east and west of Pingshan County, the middle and south of Xingwen County, the middle and west of Junlian County, and LL type was scattered in the northeast and south of Yibin City.

3. The difference of human activities was the main factor that affects the spatial differentiation of health level of the land-use ecosystem in the whole city, followed by the difference of natural system resilience, and the other factors were soil properties, landform and policy regulation. Finally, it was concluded that tightening the upper limit of capacity, holding the ecological bottom line, insisting on the intensive utilization of land, optimizing the spatial layout of production, life and ecology, adjusting the industrial structure, and developing ecotourism will become the necessary measures for Yibin City to improve the ecological health level of land-use and build a famous ecological city of landscape culture.

\section{REFERENCES}

Chen, P. 2007. Assessment of regional ecological health based on remote sensing and GIS landscape scale: a case study of the new area of bay cities. Acta Scientiae Circumstantiae, 27(10): 1744-1752.

Gao, J.Z., Xia, M.L., Meng, Z. and Liu, Y.Z. 2017. Diagnosis of land-use and ecological health under PSR framework. Jiangsu Agricultural Sciences, 45(11): 240-243.

Hao, L.X., Sun, R.H. and Chen, L.D. 2014. River ecosystem health assessment in Haihe River Basin. Environmental Science, 35(10): 3692-3701.

He, X., Jiang, G.H., Zhang, R.J., Ma, W.Q. and Zhou, T. 2015. Spatial and temporal change analysis of land-use ecological health based on PSR model taking Pinggu District of Beijing as an example. Journal of Natural Resources, 12: 2057-2068.

Huang, L.J. and Yang, P. 2019. Spatio-temporal evolution characteristics and influencing factors of land ecological security in the Yangtze River Economic Belt. Resources and Environment in the Yangtze Basin, 28(8): 1780-1790.

Jiang, W.G., Pan, Y.Z., Hou, P., Li, X., Ji, W. and Zheng, J.R. 2009. Comprehensive assessment of wetland ecosystem health in Dongting Lake area. Geographical Research, 28(6): 1665-1672.

Liu, J.X. and He, W. 2018. Study on spatial differentiation and evolution mechanism of rural areas in Sichuan Province. Journal of Sichuan Normal University (Natural Science Edition), 41(01): 122-130.

Liu, X.B., Zhen, Y. and Chen, Y.J. 2017. Characteristics of precipitation change in Yibin City in recent 60 years. Journal of Neijiang Teachers College, 32(4): 73-77.

Ma, M.R., Han, H., Wang, H.B., Yang, J. and Qu, W.H. 2014. Ecosystem health assessment of Chongming County Based on RS and GIS. Ecological Science, 33(4): 788-796.

Pan, Y.Z., Shi, P.J., Zhu, W.Q., Gu, X.H., Fan, Y.D. and Li, J. 2004. Remote sensing quantitative measurement of ecological assets of terrestrial ecosystems in China. Scientia Sinica, 34(4): 375-384.

Wang, J.A., He, C.Y., Dong, Y.C., Gao, L. and Xu, W. 2002. Analysis of driving forces of land-use change in urban-rural transition area of Beijing. Advance in Earth Sciences, 17(2): 201-208.

Wei, F. 2017. Ecosystem health assessment at township, town and sub-district level. Wei Fang: Lanzhou Jiaotong University.

Wei, Y.C., and Zhang, L.Q. 2020. Spatiotemporal pattern and obstacle factors of land eco-security early warning in Henan province. Research of Soil Land Water Conservation, 27(3): 238-246.

Xie, G.D., Zhen, L., Lu, C.X., Xiao, Y. and Chen, C. 2008. A value-based approach to ecosystem services based on expert knowledge. Journal of Natural Resources, 23(5): 911-919.

Xu, M.D., Li, J., Peng, J., Niu, J. and Cao, L. 2010. Ecosystem health assessment based on RS and GIS. Ecology and Environmental Sciences, 19(8): 1809-1814.

Zhang, J., Zou. T., Lu, X., Yi, K., Tong, Z. and Liu, X. 2011. The application of fuzzy comprehensive evaluation in land-use and ecological health evaluation. Science and Technology Innovation Herald, 29(19): 34-39.

Zhang, X.Q. and Shi, P.J. 2010. Assessment of urban ecosystem health in Lanzhou based on PSR model. Journal of Arid Land Resources and Environment, 24(3): 77-82.

Zhao, M., Yu, J., Chen, P.M., Feng, X. and Nie, Y.K. 2015. Research progress of ecosystem health assessment in the gulf. Journal of Anhui Agricultural Sciences, 35: 8-11.

Zhao, Y.T., Li, W.L., Chen, D., Yu, C., Zhao, X.L. and Xu, J. 2017. Dynamic evaluation of grassland ecosystem health in Alpine pastoral area - taking Gannan as an example. Practaculture Science, 34(1): 16-29.

Zhu, W.H., Guo, Y.L., Sun, P., Miao, C.Y. and Cao, G.L. 2012. Health assessment of wetland ecosystem in the lower reaches of Tumen River. Acta Oecologica, 32(21): 6609-6618. 